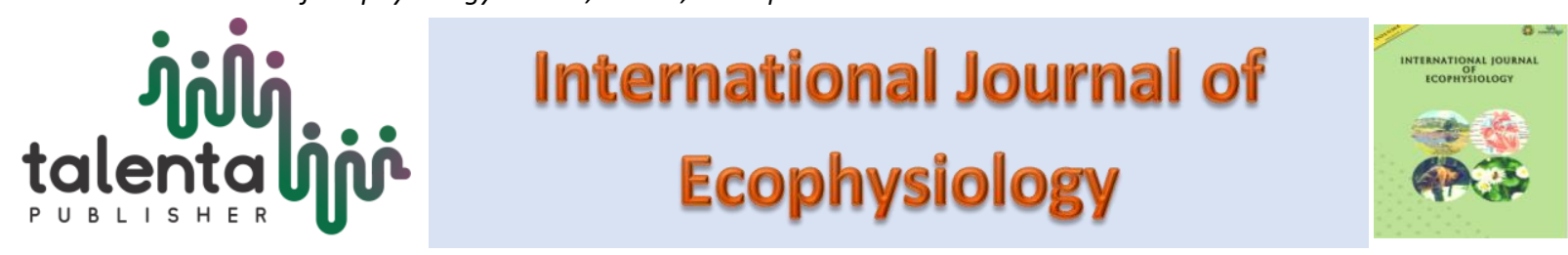

\title{
Inventory of Mango Diversity (Mangifera L.) in Bengkulu Province
}

\author{
Fitmawati $^{1 *}$, Syaiful ramadhan ${ }^{1}$, Nery Sofiyanti ${ }^{1}$ \\ ${ }^{I}$ Department of Biology, Faculty of Mathematics and Natural Sciences, Universitas Riau, Pekanbaru \\ Indonesia
}

\begin{abstract}
Mango (Mangifera L.) is a horticulture crop that grows in tropical regionthat has high diversity in Bengkulu Province. However, its diversity in this province has not been revealed, whereas on the other hand mango diversity is currently endangered due to the conversion of forests from natural habitat to plantation and industry. This study was aimed to determine the mango diversity in Bengkulu using morphological characters. All of the speciemens were collected from the field using exploration method that conducted from September 2016 to March 2017. A total of 17 individuals of mango were examined, and classified into seven mango species. The examination was conducted on the morphological characters, these characters were then scored and analyzed using NTSYSpc 2.02. The coefficient of similarity of 17 mango trees ranges from 0.45 to 0.80 . Dendrogram showed that the clustering of mango was not based on the origin of the population but based on the morphological characters. The first group comprises six individuals and the second group consists of 11 individuals.
\end{abstract}

Keyword: Mangifera L., mango, morphological, Bengkulu Province

Received 1 November 2019 | Revised 20 December2019| Accepted 22 January2020

\section{Introduction}

Indonesia is a tropical country with a high level of biodiversity, one of which is mango (Mangifera sp.). The Mangifera clan is known to originate from tropical regions around Asia which then spread and are cultivated almost all over the world. Mango is one of the horticulture plants whose fruit is excellent for consumption. Mango germplasm in Indonesia is quite large, and there are an estimated 292 mango cultivars in Indonesia. In 2004 the harvest area was 185,773 ha with a production of $1,437,665$ tons. Sumatra Island has a high diversity of flora including the southern Sumatra region. These types of Mangifera have a unique ability to adapt

\footnotetext{
*Corresponding author at: 1Department of Biology, Faculty of Mathematics and Natural Sciences, Universitas Riau, Pekanbaru Indonesia

E-mail address: fitmawati2008@yahoo.com
} 
to the tropics, such as being able to flower at high rainfall and have resistance to fruit loss. This causes Sumatra to be a potential source of Mangifera germplasm typical of tropical regions [1].

Mango germplasm in Indonesia is quite large and there are an estimated 292 mango cultivars in Indonesia. Mangoes have high diversity both morphologically, anatomically, physiologically, and genetically. This can be seen in terms of appearance or character of leaves, fruit, taste, color, and aroma. In addition, diversity can occur when flowering and fruiting. The use of morphological characters is the easiest way to determine the level of kinship between mangoes and is the most frequently used method in mango characterization [2].

Sumatra Island has a high diversity of flora including the southern Sumatra region. These types of Mangifera have a unique ability to adapt to the tropics, such as being able to flower at high rainfall and have resistance to fruit loss. This causes Sumatra to be a potential source of Mangifera germplasm typical of tropical regions [1]

Species diversity and mango cultivars in Bengkulu province are threatened with extinction along with the decline in forest areas as their natural habitat caused by deforestation, habitat change, industrialization, expansion of oil palm plantations and so forth. The deforestation rate in Sumatra is 268,000 ha / year or $22.8 \%$ of the total deforestaion in Indonesia, estimated in less than a quarter of a century has lost tens to hundreds of wild mangoes that have not been explored and identified. Diversity studies (exploration, identification and characterization) in Bengkulu Province need to be carried out in order to minimize species depletion, especially Ssp Mangifera plants. which exists. Exploration is the activity of tracking or exploring, searching, collecting and researching the type of germplasm carried out to secure it from extinction [3]. This activity was carried out to save local cultivars and their close relatives who are still wild. The initial approach in this activity is to inventory plants and followed by characterization of morphological and agronomic characters. Morphological characterization of mango plants is needed to identify the existing germplasm. Radford [4] states that morphological evidence is the basis in determining the characteristics, identification and kinship of a plant. Therefore the use of morphological characters is a fast, precise and easy way to see the diversity of mango plants (Mangifera sp.). Besides agronomic character is also important to be used to characterize cultivated plants. According to Sumantri [5], agronomy is the study of all biophysical aspects related to efforts to improve crop cultivation to obtain maximum production.

\section{Materials and Methods}

Sampling locations were carried out in Bengkulu Province using survey and observation methods. Morphological and agronomic observation data are presented in the form of scores and then used to create a genetic similarity matrix using the SIMQUAL (Similarity for Qualitative Data) procedure. Furthermore, this similarity matrix is used for Sequential Angglomerative, 
Hierarchical and Nested (SAHN) grouping clustering analysis using UPGMA (Unweighted Pair group method with arithmetic average) using a NTSYS-pc 2.02 computer program [6] and morphological character variability data analysis using using Pearson correlation in the Minitab 16.0 program.

\section{Result and Discussion}

\subsection{Morphological Diversity of Mangoes (Mangifera) in Bengkulu Province}

The genus Mangifer is a plant that grows wild in tropical rain forests and has been partly cultivated. Mango in Bengkulu Province is found in the yard of people's houses and plantations. Based on the results of the study there were obtained / found 7 types of Mangifers that were found include Mangifera odorata Griff., Mangifera sumatrana Mig., Mangifera lalijiwa Kosterm., Mangifera indica L., Mangifera zeylanica Hook.f., Mangifera laurina Blume.

Table 1. Samples of mango trees in Bengkulu Province

\begin{tabular}{cll}
\hline No & \multicolumn{1}{c}{ Species } & \multicolumn{1}{c}{ Sample Code } \\
\hline 1 & Mangifera odorata Griff. & KMO6 \\
2 & Mangifera sumatrana Mig. & KMS15 \\
3 & Mangifera lalijiwa Kosterm. & KMLA19 \\
4 & Mangifera indica L. & KMI8, KMI14, KMI17 \\
5 & Mangifera zeylanica Hook.f. & KMZ16 \\
6 & Mangifera laurina Blume. & MLUK7, KMLU11, KMLU20, KMLU30, \\
& & KMLU37 \\
7 & Mangifera foetida Lour. & KMF2, KMF3, KMF13, KMF23, KMF24 \\
\hline Total & \multicolumn{1}{c}{ 17 individuals } \\
\hline
\end{tabular}

Mango trees that come from seeds generally grow upright, strong and tall while those that come from joints or patches are shorter and branches stretch. Mango trees are generally found in residents' homes. Mango trees that are found are straight trunked, without root boards and light brown to dark brown bark. Tree canopy forms were found from 7 types of mangoes, namely oblong (longitude) as many as 3 types namely $M$. foetida (4 individuals), $M$. indica (1 individual), and $M$. laurina ( 3 individuals), broad pyramid shape as many as 3 types namely $M$. foetida (1 individual), M. laurina (1 individual), and M. lalijiwa (1 individual), 4 types of semicircular form namely $M$. indica (2 individuals), M. laurina (1 individual), M. sumatrana (1 individual), and M. zeylanica (1 individual), and 1 type of spherical, namely M. odorata (1 individual) (Figure 1). These tree canopy forms are found evenly in each area in Bengkulu. Suggested that there are variations in the shape of the canopy caused by environmental factors surrounding the plant, so that in general strategies to adapt to changes in morphological and physiological characters. Similarity Coefficient of Mango Morphological Character (Mangifera) in Bengkulu Province. 


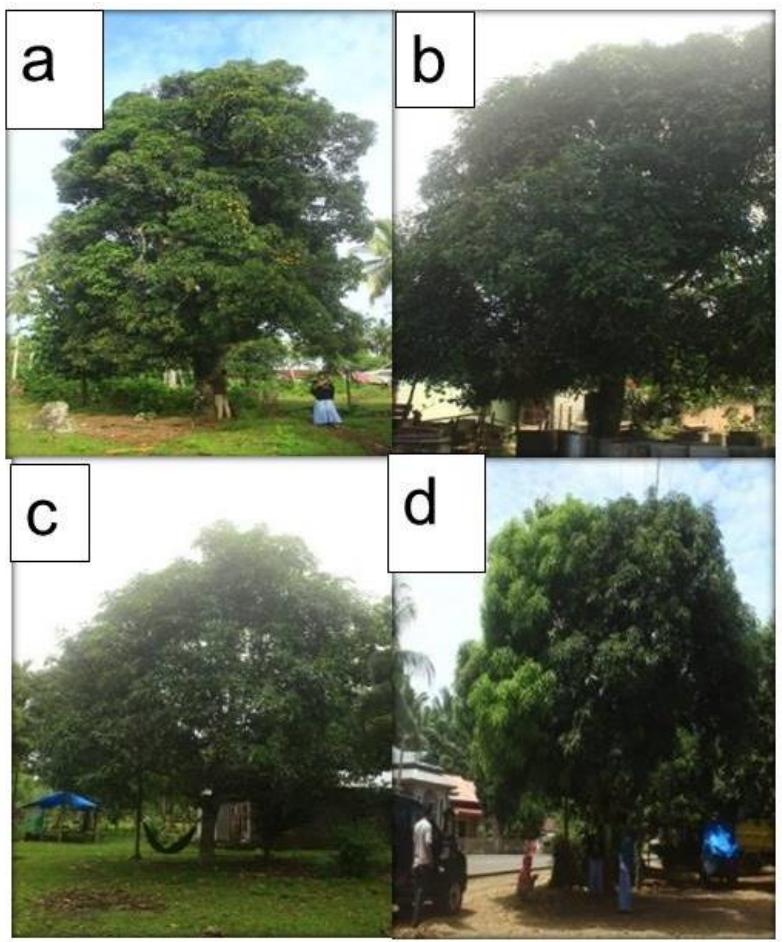

Figure 1. Mango Tree Canopy, (a) oblong (longitude), (b) spherical (round), (c) broad pyramid, (d) semi-circular.

The growth of mango trees that blend with other plants results in variations in the tree canopy. State that mango trees planted in a mixed stand of taller trees will have well-arranged lateral branches and retain their canopy shape while plants planted in open land, growth is high, mate lateral branch pairs are located close together, resulting in the formation of a very tightly shaped round canopy [7].

Mango leaves are single leaves with pinnate leaves [8]. Younger leaves are usually reddish, purplish, or yellowish in color which will later turn on the upper surface to shiny green, while the lower surface is light green. Observations of qualitative characters in the mango leaf organ include the length of the petiole, width of the petiole, leaf blade shape, leaf length, leaf width, leaf tip, and leaf base. Leaf shape forms observed in 7 types of mangoes found in Bengkulu Province included elliptic forms of 4 types namely M. foetida (4 individuals), M.indica (2 individuals), M. laurina (2 individuals), and M. lalijiwa ( 1 individual), and 6 types of oblong form namely M.odorata (1 individual), M. foetida (1 individual), M. indica (1 individual), M. sumatrana (1 individual), M. laurina (3 individuals), and M. zeylanica (1 individual) (Figure 2). The shape of obtuse leaves is 1 type namely M. foetida ( 2 individuals), acute as many as 5 types namely $M$. odorata (1 individual), $M$. foetida (3 individuals), $M$. indica (1 individual), $M$. laurina ( 3 individuals), and $M$. sumatrana (1 individual), and acuminate 4 types namely $M$. indica (2 individuals), M. laurina (2 individuals), M. zeylanica (1 individual), and M. lalijiwa (1 individual).The shape of the base of obtuse leaves is 1 type namely $M$. odorata (1 individual), and acute 6 types namely M. foetida (5 individuals), M. indica (3 individuals), M. laurina (5 individuals), M. sumatrana (1 individual) ), M. zeylanica (1 individual), and M. lalijiwa (1 
individual) (Figure 4). Corrugated leaf edges, leaf reinforcement generally pinnate and arise, the nature of the leaves are warm and stiff.
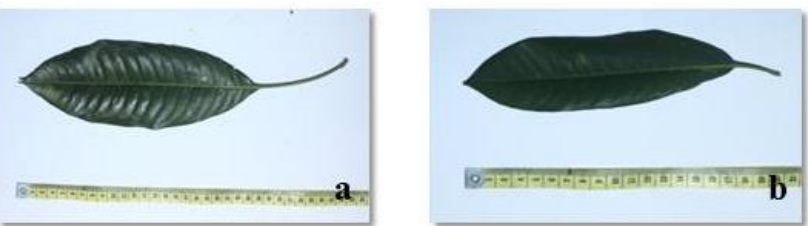

Figure 2. Leaf shape of mango leaves (a) Elliptic, (b) Oblong
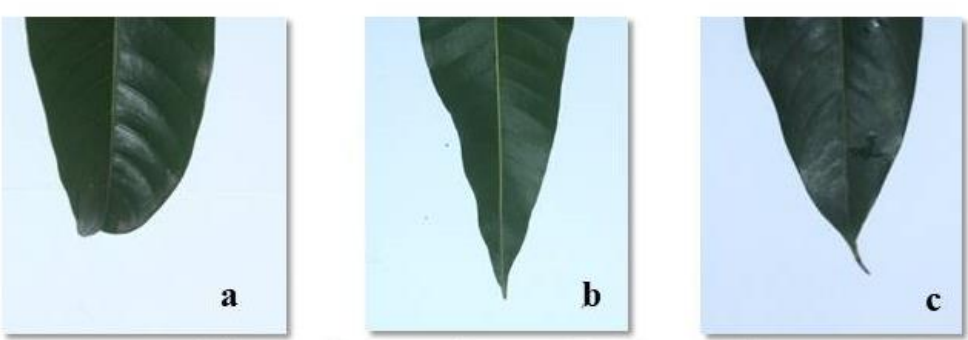

Figure 3. Leaf shape of mango leaves (a) Obtuse, (b) Acute, (c) Acuminate
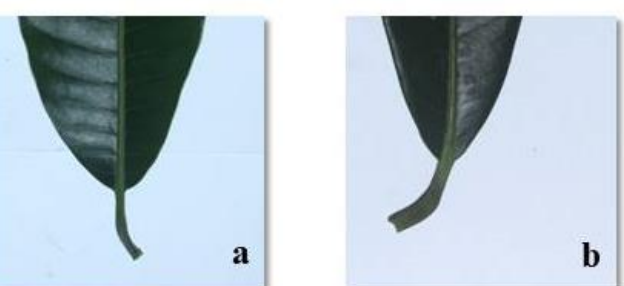

Figure 4. Leaf base shape,(a). Obtuse, (b). Acute.

The length of the petiole ranges from $0.5 \mathrm{~cm}$ to $6.6 \mathrm{~cm}$ with an average of $3.65 \mathrm{~cm}$, the length of the leaf ranges from $11 \mathrm{~cm}$ to $26 \mathrm{~cm}$ with an average of $18.27 \mathrm{~cm}$, the width of the leaves ranges from $3 \mathrm{~cm}$ to $10 \mathrm{~cm}$ with an average of $5.48 \mathrm{~cm}$. Observations of qualitative characters in leaf organs (leaf edge shape, leaf top surface, leaf bottom surface, cross section of leaf bone mother, and leaf reinforcement) did not show any variation between individuals and other individuals. Based on the results of the scoring of 38 morphological and agronomic characters of mango on 17 samples of mango in Bengkulu Province, a similarity coefficient matrix was obtained with a range of values ranging from 0.45 to 0.80 (Table 2.). The highest coefficient value is obtained for the type of Mangifera foetida, namely KMF2 (oval macola) with KMF3 (milk macaws), and the lowest coefficient value is obtained by the type of Mangifera foetida yakni KMF13 with Mangifera sumatrana namely KMS15. The matrix value indicates the greater the number, the higher the similarity owned by these individuals. Conversely, the smaller the number, the level of similarity owned by these individuals the lower.

Mangifera foetida (KMF2 and KMF3) have the highest similarity coefficient because they have 13 character differences and 25 character similarities, namely leaf shape, leaf base, leaf length, leaf width, leaf width, stem width, neck curve, mature skin color, skin surface texture, fruit flesh color, fruit flesh texture, skin thickness, skin sticking to the pulp, sticking fiber to the seeds, sticking to the skin fiber, fiber length, moisture content, fruit aroma, seed length, seed width, 
seed thickness, quantity of fiber to the seeds, quantity fiber in seeds, seed weight, embryo and cotyledon weight, and cotyledon form.

Mangifera foetida (KMF13) and Mangifera sumatrana (KMS15) types have the lowest similarity coefficients because they have 30 character differences and 8 character similarities, namely, leaf base, leaf length, leaf width, fruit tip, fruit sinus, skin surface texture, cotyledon shape, and fruit weight.

Fruit weight per fruit ranges from 100 grams to 852 grams with an average of 294 grams. Skin thickness ranges from $0.1 \mathrm{~cm}$ to $0.6 \mathrm{~cm}$ with an average of $0.26 \mathrm{~cm}$, thick flesh of the fruit ranges from $0.2 \mathrm{~cm}$ to $3.2 \mathrm{~cm}$ with an average of $1.64 \mathrm{~cm}$, fiber length ranges from $0.4 \mathrm{~cm}$ to $9.6 \mathrm{~cm}$ with an average of $4.65 \mathrm{~cm}$. The color of the flesh of the fruit varies, namely $5 \mathrm{bright}$ yellow types namely $M$. foetida (4 individuals), M. indica (2 individuals), M. laurina (1 individual), M. sumatrana (1 individual), M. zeylanica (1 individual), yellow as many as 3 types namely $M$. odorata ( 1 individual), $M$. indica ( 1 individual), M. laurina (3 individuals), and pale yellow as many as 3 types namely $M$. foetida ( 1 individual), M. laurina ( 1 individual) 1 individual), M. lalijiwa (1 individual) (Figure 1.). Seed weights range between 11 grams and 143 grams with an average of 48.5 grams, Brix meters between 8 and 21 with an average of 15.1 .
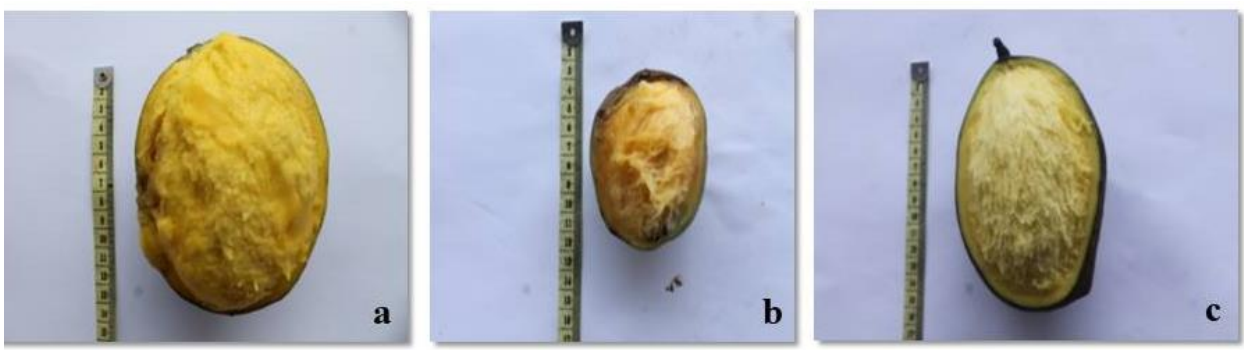

Figure 5. The color of ripe mango flesh is (a) bright yellow, (b) dark yellow, (c) pale yellow
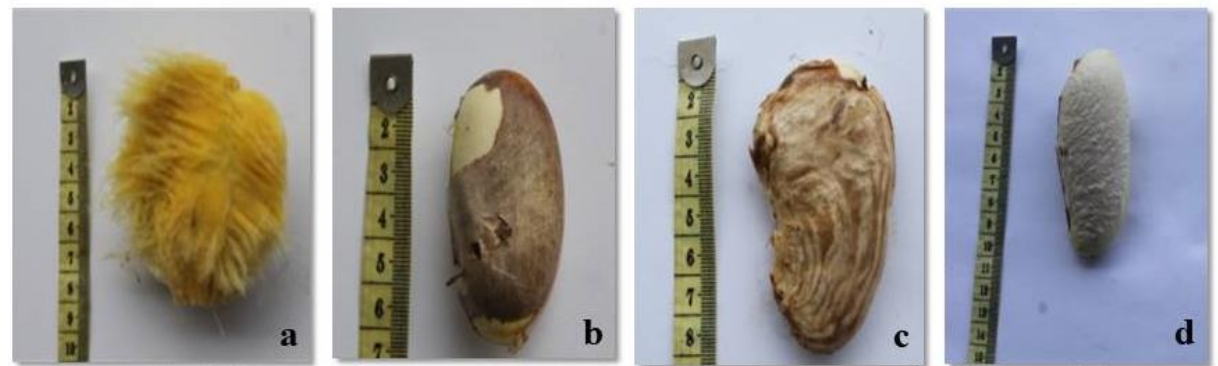

Figure 6. (a) fiber in mangoes, and cotyledon form in mangoes (b) Oblong, (c) Reniform, (d) Ellipsoid.

Mango seeds in Bengkulu have a high diversity seen from seed shape, seed length, seed width, seed weight, seed thickness, seed fiber content (Figure 5 and 6). Seed lengths range between 4 $\mathrm{cm}$ and $14.7 \mathrm{~cm}$ with an average of $8.2 \mathrm{~cm}$, seed widths range between $2.1 \mathrm{~cm}$ and $5.3 \mathrm{~cm}$ with an average of $3.9 \mathrm{~cm}$, thick seeds range between $1.0 \mathrm{~cm}$ and $4.2 \mathrm{~cm}$ with an average of $2.07 \mathrm{~cm}$. Mango cotyledon forms in Bengkulu include 6 types of reniform, namely M. odorata (1 
individual), $M$.foetida (1 individual), $M$. indica (3 individuals), $M$. laurina (4 individuals), $M$. sumatrana (1 individual), and M. zeylanica (1 individual), 2 types of oblong, namely M. foetida (4 individuals), M. lalijiwa (1 individual), and ellipsoid as many as 1 type M. laurina (1 individual). Weight of embryos and cotyledons ranged between 5.0 grams and 52.0 grams with an average of 18.4 grams. Mango cotyledons that are found include monoembrioni or single seed, and Polyembrioni.

\subsection{Analysis of Mango Cluster (Mangifera) in Bengkulu Province}

Based on cluster analysis of 38 morphological and agronomic characters of mango in Bengkulu Province, it produces a dendrogram with similar coefficients ranging from 0.57 to 0.80 (Figure 4.9). Mango grouping in Bengkulu Province is not based on the region of origin but based on the grouping of 38 certain morphological features. The whole mangoes unite at $57 \%$ similarity, and form 2 main groups, each divided into group I and group II. Group I consisted of 6 individuals namely Mangifera foetida namely (KMF2, KMF3, KMF13, KMF23, KMF24), and Mangifera odorata namely (KMO6) and group II consisted of 11 individuals namely Mangurera laurina types (KMLU7, KLU11, KMLU20, KMLU30, KMLU30), K37), namely Mangifera zeylanica (KMZ16), Mangifera lalijiwa namely (KMLA19), Mangifera sumatrana namely (KMS15), and Mangifera indica namely (KMI8, KMI14, KMI17). Group I separated from group II at a similarity rate of $58 \%$. Group I is further divided into 2 sub-groups namely IA, I-B and group II is also divided into 2 sub-groups namely II-A and II-B.

Group I-A grouped at a level of similarity of 65\% consisting of 3 individuals namely Mangifera foetida namely (KMF2, KMF3) and Mangifera odorata (KMO6). These individuals are grouped based on 14 character equations, namely the shape of leaf tips, leaf length, sticking skin on pulp, sticking fibers on seeds, sticking fibers on skin, fiber length, moisture content, fruit aroma, seed length, seed width, seed width, seed thickness, seed weight, embryo and cotyledon weight, brix meter.

Group I-B grouped at a 63\% similarity level consisting of 3 individuals namely Mangifera foetida (KMF13, KMF23, KMF24). These individuals are grouped based on 11 character equations, namely the shape of the crown, the shape of the leaf blade, leaf base, leaf length, leaf stalk length, fruit shape, fruit base, mature skin color, skin attachment to the pulp, moisture content, and fruit aroma.

Group II grouped at a similarity level of $64 \%$. Group II-A grouped at a $66 \%$ similarity level consisting of 7 individuals namely Mangifera laurina (KMLU7, KMLU37, KMLU20, KMLU30, KMLU11), Mangifera zeylanica (KMZ16), and Mangifera lalijiiwa (KMLA19). These individuals are grouped based on 6 character similarities, namely leaf base, leaf width, neck curve, skin surface texture, fruit aroma, fruit weight. 
Group II-B grouped at a 66\% similarity level consisting of 4 individuals namely Mangifera indica (KMI8, KMI17, KMI14), Mangifera sumatrana (KMS15). These individuals are grouped based on 9 character equations, namely the base of the leaf, the base of the fruit, the texture of the surface of the skin, the texture of the fruit flesh, the attachment of fibers to the seeds, the aroma of the fruit, the shape of the cotyledons, the weight of the fruit.

The results of cluster analysis are similarities based on the morphological character of not clustering based on the region of origin of the growth of mangoes. This grouping shows that individuals from different regions can join the same group of individuals. Conversely, individuals who are in the same location may not necessarily belong to the same group of individuals. Grouping is not related to geographical location but is influenced by environmental factors [9].

Classification that occurs because of the similarity of characters that exist in individual mangoes in Bengkulu Province. Similarities using morphological nature data can determine genetic kinship relationships [10]. The lower the variation owned by individuals, the higher the level of similarity between existing accessions, so the closer the kinship. Information on kinship relationships is important in assembling superior varieties. The more kinship between the elders then produces a narrow variation. Conversely, the more unrelated crosses between elders produce a large variation [11].

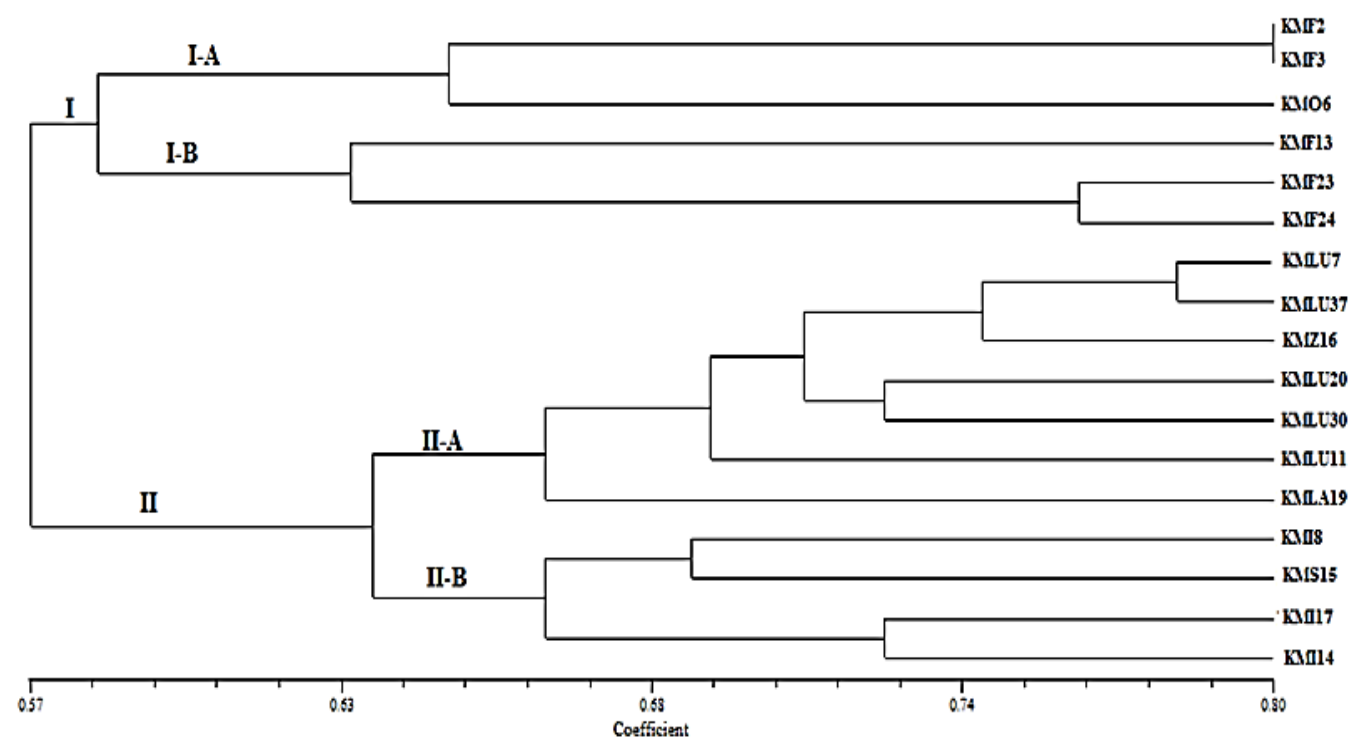

Figure 7. Dendrogram of 17 Mango Trees in Bengkulu Province 


\section{Conclusion}

From the results of research that has been done about the Existence of Land Macrofauna on Oil

Palm Plantation Land of PT. Supra Matra Abadi can be concluded as follows.. The results of the study in Bengkulu Province obtained 7 types of Mangifera, including M. odorata, M. sumatrana, M. lalijiwa, M. indica, M. zeylanica, M. laurina, and M. foetida. The highest phenotypic similarity coefficient (Kf) values are $80 \%$ are between $\mathrm{KMF} 2$ individuals and KMF3 while the lowest phenotypic coefficient (Kf) value is 45\%, there are KMF13 individuals with KMS15. The results of cluster analysis show the diversity of mangoes in Bengkulu Province amounted to $57-80 \%$ and formed 2 main groups but did not group by area of origin.

\section{Akcnowledgment}

The author would like to thank the Ministry of Research and Technology of the Higher Education which has funded this research in the 2016 Competency Grant program.

\section{REFERENCES}

[1] Fitmawati, Suwita A, Sofiyanti N \& Herrnan. Analisis Kekerabatan Mangifera dari Sumatera Tengah. Floribunda 4(7): 169-179. 2013.

[2] Sherman A, Rubinstein M, Eshed R, Benita M, Ish-Shalom M, Sharabi-Schwager M, Rozen A, Saada D, Cohen Y, Ophir R. Mango (Mangifera indica L.) germplasm diversity based on single nucleotide polymorphisms derived from the transcriptome. BMC Plant Biol. 2015 Nov 14;15:277.

[3] Kusumo, Surahmat, Khasanah, Maharani, Moeljopawiro, Sugiono. 2002. Panduan Karakterisasi dan Evaluasi Plasma Nutfah Talas. Departement Pertanian Badan Penelitian dan Pengembangan Pertanian Komisi Nasional Plasma Nutfah.

[4] Radford, A. E., 1986. Fundamentals of Plants Systematics. Harper and Row Publishers. Inc. New york.

[5] Sumantri.1980. Pengantar Agronomi. PT. Gramedia : Jakarta.

[6] Rohlf FJ., NTSYSpc Numerical Taxonomy and Multivariate Analysis System Version 2.2 Getting Started Guide. Department of Ecology and Evolution State University of New York Stony Brook, NY 11794-5245. 2009.

[7] Zhang C, Dehong Xie, Tianqi Bai, Xinping Luo, Faming Zhang, Zhangguang Ni and Yufu Chen. Diversity of a Large Collection of Natural Populations of Mango (Mangifera indica Linn.) Revealed by Agro-Morphological and Quality Traits. Diversity, 12, 27. 2020.

[8] Ko Y, Yao KS, Chen CY, Lin CH.. First Report of Gray Leaf Spot of Mango (Mangifera indica) Caused by Pestalotiopsis mangiferae in Taiwan. Plant Dis. 91(12):1684. 2007

[9] Dinesh R, Kundapura V Ravishankar, Bhuwon Ratna Sthapit, Genetic Diversity Studies in Certain Indigenous Mango (Mangifera indica L) Varieties. Indian J. Plant Genet. Resour. 28(1); 153-160. 2015

[10] Miftahorrachman. Hubungan Kekerabatan Genetik Empat Aksesi Plasma Nutfah Pinang Asal Sulawesi Utara dan Sumatera Utara. B. Palma Vol. 13 No. 1 : 17 - 21. 2012.1

[11] Wolf DA. The Elderly and Their Kin: Patterns of Availability and Access. National Research Council (US) Committee on Population; Martin LG, Preston SH, editors. 